\title{
DIETARY FLAVONOID INTAKE AND COGNITIVE PERFORMANCE IN OLDER ADULTS WITH ALZHEIMER'S TYPE DEMENTIA
}

\author{
K. Kent ${ }^{1}$, S. Roodenrys'2, K.E. Charlton ${ }^{1}$, R. Richards², O. Morgan², H. Gilbert ${ }^{2}$
}

\begin{abstract}
Background: Dietary flavonoid intake and intake of flavonoid subclasses has been associated with improved cognitive performance. However, the association between flavonoid intake and cognitive performance in older adults with Alzheimer's type dementia has not been investigated. Objectives: To estimate dietary total flavonoid intake and intake of flavonoid subclasses in older adults with Alzheimer's type dementia and assess the relationship of flavonoid intake with measures of cognition. Design: Cross sectional analysis. Setting: Community dwelling older adults in NSW, Australia. Participants: Older adults (+65y) with mild to moderate dementia $(n=49)$. Measurements: A 24 h diet recall was collected with help from a carer and used to estimate flavonoid intake. A battery of cognitive tasks assessed cognitive performance of several cognitive domains. Results: Pearson and spearman correlation coefficients identified an association between flavonoid intake and executive function ( $\mathrm{r}=0.319, \mathrm{p}=0.025$ ). After controlling for depression, the relationship was reduced. Conclusion: The identified association between cognitive functioning, depression and flavonoid intake in older adults with Alzheimer's type dementia warrants further research in a larger sample.
\end{abstract}

Key words: Flavonoid, cognition, dementia.

\section{Introduction}

Flavonoids are naturally occurring plant-based phytochemicals, which are abundant in the human diet. The structure and sources of flavonoids has been well established $(1,2)$. Flavonoids are a subclass of polyphenols and encompass a wide group of compounds that are divided into six major classes: anthocyanidins, flavanols, flavanones, flavones, flavonols and isoflavones (1). A growing body of evidence suggests that flavonoids are non-nutritive bioactive compounds, which significantly contribute to the antioxidant activity of individual fruits and vegetables and are consequently credited with the observed health benefits (3). Flavonoids are widespread across many food sources and are found in particularly high concentrations in fruits and vegetables, wine, tea, cocoa, and soy (4). In older Australian adults, major dietary sources of flavan-3ols and flavonols are tea (black and green) and apples; flavanones are provided by citrus fruits and juices; flavones are consumed through parsley and tomatoes; and berries and red wine provide anthocyanins (5).

1. School of Medicine, Faculty of Science, Medicine and Health, University of Wollongong, Australia; 2. School of Psychology, Faulty of Social Sciences, University of Wollongong, Australia

Corresponding Author: K. Kent, School of Medicine, Faculty of Science, Medicine and Health, University of Wollongong, Australia, e-mail:kc582@uowmail.edu.au
Isoflavones are largely provided by the consumption of soy-based products (6).

Total dietary flavonoid consumption has been association with improved cognitive performance and a preservation of cognitive function with ageing (7-9). More focussed research on specific flavonoid subclasses has revealed that the sub-groups flavanols, anthocyanins and flavanones may provide the most beneficial effects in the area of neuroprotection (10). There has been a particular focus in animal models, on the provision of anthocyanin rich foods, such as blueberries, when investigating cognitive outcomes, with promising results (11-13). Preliminary human trials have also begun to link anthocyanin-rich food consumption with improvements in cognitive outcomes (14-18). A high consumption of total dietary flavonoids has also been linked with a reduced risk of developing a neurodegenerative disease, such as dementia (19). However, the association between flavonoid intake and cognitive performance in older adults with Alzheimer's type dementia has not been investigated to date.

The mechanisms by which flavonoids provide neuroprotection are not well elucidated and the evidence remains largely pre-clinical. This is partially related to the quick and extensive metabolism of dietary flavonoids into metabolites with differing and largely unknown biological activities (1). In animal models, 
specific flavonoids including the flavanols catechin and epigallocatechin gallate (20) have been shown to reduce neuroinflammation and scavenge free radicals within the brain (2), a function which has been related to neuroprotection. Additionally, flavonoids, including the flavanone hesperitin have been shown to provide a range of positive neuronal effects to limit neurodegeneration, including a potential to protect neurons against injury and improve neuronal morphology $(2,21)$. Flavonoid supplementation has also been shown to up-regulate processes that promote learning, memory and cognition (1). Flavonol-rich cocoa consumption has shown to increase cerebrovascular blood flow, which is associated with improved cognition (22). Presently, it is unclear how many, or if all flavonoids exert such effects (1).

Evidence is mounting for the positive protective effects of flavonoid consumption for the development of dementia $(7,19,23)$, including consumption of flavonoid rich fruits and vegetables, juices and wine $(24,25)$. However, it is also important to investigate the relationship between flavonoid consumption in older adults living with dementia and cognitive performance outcomes. This evidence could be utilized to indicate if dietary interventions with flavonoids may be warranted. It is well documented that older adults with dementia develop eating difficulties, resulting in low food intake, as dementia progresses (26). This can be related to a myriad of difficulties including dysphasia, lack of appetite, confusion about the need to eat and the loss of the ability to recognize food (27). The total dietary intake and significant sources of dietary flavonoids in older adults living with dementia has not been assessed and may differ from estimations for healthy adults aged $65+$ yrs.

The aim of this study was to estimate the total dietary intake and main sources of flavonoids in older Australian adults with Alzheimer's type dementia and to assess the relationship between dietary flavonoid intake and cognitive performance.

\section{Methods}

This study was approved by the University of Wollongong and Illawarra Shoalhaven Local Health District Human Research Ethics Committee (HE11/175) and complied with current laws governing ethics in research. The current study analysed the baseline data of a randomised controlled trial, which investigated the impact of anthocyanin-rich cherry juice on cognitive outcomes in older adults with dementia (17)

Community dwelling older adults (65+yrs) with mild to moderate Alzheimer's type dementia (as diagnosed by a hospital-based geriatrician) were recruited to the study from an outpatient clinic. Dietary data was collected by a trained nutritionist (KK) (with assistance and confirmation provided from a carer) from a single 24-h food recall. The dietary data was analysed using the Foodworks dietary analysis package (Xyris software, version 5, 2007, Highgate Hill, QLD, Australia) (28). As dietary data relating to flavonoid content of foods is not integrated into the Xyris software, the food items were manually cross-referenced with the USDA database for the flavonoid content of selected foods (release 3.1) (29) to estimate total flavonoid consumption and the flavonoid subclasses anthocyanins, flavones, flavanones, flavonols and flavan-3-ols. A Mini Nutritional Assessment (30) was conducted as a measure of malnutrition and Lawton's Instrumental Activities of Daily Living Scale (31) measured functional ability. Anthropometric and demographic information, including education, was collected (Table 1), with assistance from a guardian or carer as appropriate.

A battery of cognitive assessments was administered by a single trained researcher (KK). These included measures of mood (32), verbal learning and memory (33), working memory (34), semantic memory (35), executive function $(36,37)$ and short-term memory $(38)$ (Table 2).

To assess the relationship between flavonoid intake and cognitive performance, bivariate correlations with Pearson and Spearman coefficients (as appropriate) were performed and then repeated after controlling for depression, as measured by the Geriatric Depression Scale (GDS) (32). Multiple regression analysis was performed to confirm the effect of flavonoid intake on cognitive outcomes that were identified as significant by the correlations, with age and education included in the models as covariates.

\section{Results}

Forty-nine participants volunteered to take part in the study; their anthropometric and demographic characteristics are found in Table 1.

\section{Figure 1}

Percentage contribution of flavonoid subclasses to total flavonoid intake

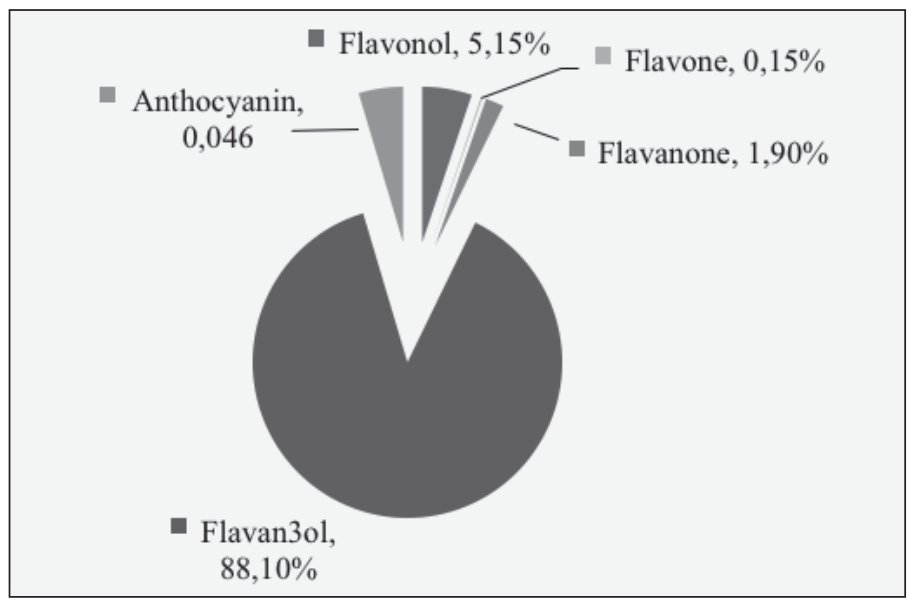

Analysis of the $24 \mathrm{~h}$ dietary recall calculated total flavonoid intake to be $510.2 \pm 374.8 \mathrm{mg} /$ day, with a range of $5.9-1,524.2 \mathrm{mg} /$ day. Black tea contributed 
$80 \%$ of total dietary intake and was the most notable dietary source of flavonoids. Other notable sources were green tea $(7.5 \%)$, red wine $(4.5 \%)$, with apples and oranges providing $1.7 \%$ and $1.6 \%$ respectively, when combined with their fruit juices. The dominant subclass of flavonoids was flavan-3-ols; these contributed $88 \%$ of total intake (Figure 1).

Table 1

Characteristics of study participants $(n=49)$

\begin{tabular}{|c|c|}
\hline Age (years) & $79.82 \pm 6.9$ \\
\hline \multicolumn{2}{|l|}{ Gender } \\
\hline Male & 24 \\
\hline Female & 25 \\
\hline $\mathrm{BMI}(\mathrm{kg} / \mathrm{m} 2)$ & $26.1 \pm 3.5$ \\
\hline Current smokers $(\%)$ & $2.7 \%$ \\
\hline Previous smokers $(\%)$ & $40.5 \%$ \\
\hline Hand grip strength $(\mathrm{kg})$ & $33.2 \pm 6.9$ \\
\hline Mid arm circumference $(\mathrm{cm})$ & $27.1 \pm 4.2$ \\
\hline Calf circumference $(\mathrm{cm})$ & $34.1 \pm 3.6$ \\
\hline \multicolumn{2}{|l|}{ Education (count) } \\
\hline Primary & 3 \\
\hline Secondary (year 10) & 24 \\
\hline Secondary (year 12) & 10 \\
\hline Tertiary & 12 \\
\hline Mini Nutritional Assessment & $24.2 \pm 3.1$ \\
\hline Lawton's Instrumental Activities of Daily Living Scale & $6.2 \pm 2.3$ \\
\hline \multicolumn{2}{|c|}{$\begin{array}{l}\text { Ideal BMI for adults } 65 \mathrm{y}+\text { is } 22-27 \mathrm{~kg} / \mathrm{m} 2 \text { (13); Calf circumference and mean } \\
\text { mid-upper arm circumference in of } 29.2 \text { in older adults; Mini Nutritional As } \\
\text { sessment score }>23.5 \text { indicates no risk of malnutrition (14); Median maximum } \\
\text { hand grip strength are } 37.9 \mathrm{~kg} \text { and } 31.5 \mathrm{~kg} \text { for men and women aged } 50 \mathrm{y}+(15) \\
\text { Lawton's IADL scale mean score } 4.3 \text { in adults with moderate dementia (11). }\end{array}$} \\
\hline
\end{tabular}

Table 2

Cognitive instruments, domain targeted and relationship with total flavonoid intake
Total flavonoid intake was not significantly correlated with age, nutritional status or education. However, participants who displayed greater depressive symptoms (i.e. scored higher on the GDS) had a lower total flavonoid intake $(\mathrm{r}=-0.328 \mathrm{p}=0.021)$.

Total flavonoid intake was significantly correlated with verbal fluency $(\mathrm{r}=0.319 \mathrm{p}=0.025)$ (Table 2). Verbal fluency was also significantly correlated with the flavonoid subclasses flavonols $(\mathrm{r}=0.321 \mathrm{p}=0.025)$, flavan-3-ols $(\mathrm{r}=0.323 \mathrm{p}=0.023)$ and anthocyanins $(\mathrm{r}=0.298, \mathrm{p}=0.038)$. No other significant associations were identified. A regression analysis was conducted to predict verbal fluency from total flavonoid intake, with age and education as covariates. Total flavonoid intake statistically significantly predicted verbal fluency score ( $\beta=0.319, \mathrm{p}=0.025)$ controlling for age $(\beta=0.042, \mathrm{p}=0.765)$ and education $(\beta=0.219, p=0.124)$. The overall model fit was $\mathrm{r} 2=0.148$.

After controlling for depression (GDS continuous score), bivariate correlations showed no significant relationship between total flavonoid intake or flavonoid subclasses was shown (Table 2).

\section{Discussion}

The mean intake of total flavonoids (510mg/day) in this sample of older adults with mild to moderate Alzheimer's type dementia is lower than the other estimations in older Australian adults, which were $683 \mathrm{mg} /$ day (5) (from 12 day food records) and $575 \mathrm{mg} /$ day (from a single $24 \mathrm{~h}$ dietary recall) (39). However, the major dietary sources and percentage contributions from each flavonoid subclass are similar $(5,39)$. Black tea was the major dietary source of flavonoids $(80 \%)$, and this finding highlights a limited fruit and vegetable consumption in this group.

The relationship between cognitive performance on

\begin{tabular}{|c|c|c|c|}
\hline Cognitive Instrument & Domain & $\begin{array}{l}\text { Bivariate relationship total } \\
\text { flavonoid intake }\end{array}$ & $\begin{array}{l}\text { Bivariate relationship total } \\
\text { flavonoid intake controlling for } \\
\text { depression (GDS) }\end{array}$ \\
\hline The Geriatric Depression scale (12) & Mood & $\mathrm{r}=-0.367, \mathrm{p}=0.009^{* *}$ & - \\
\hline $\begin{array}{l}\text { Rey Auditory Verbal Learning } \\
\text { Test (16) }\end{array}$ & Verbal learning and memory & $\mathrm{r}=0.161, \mathrm{p}=0.270$ & $\mathrm{r}=102, \mathrm{p}=0.439$ \\
\hline Self Ordered Pointing Task (17) & Working memory & $\mathrm{r}=-0.095, \mathrm{p}=0.588$ & $\mathrm{r}=-0.046, \mathrm{p}=0.760$ \\
\hline The Boston Naming Task (18) & Semantic memory & $\mathrm{r}=0.095, \mathrm{p}=0.514$ & $\mathrm{r}=-0.019,0.899$ \\
\hline The Verbal Fluency Task (19) & $\begin{array}{l}\text { Executive function and control } \\
\text { processes }\end{array}$ & $\mathrm{r}=0.319, \mathrm{p}=0.025$ * & $\mathrm{r}=0.191, \mathrm{p}=0.198$ \\
\hline Trail Making Task (20) & Executive function & $\mathrm{r}=-0.98, \mathrm{p}=0.504$ & $\mathrm{r}=-0.051, \mathrm{p}=0.773$ \\
\hline Digit Span Backwards Task (21) & $\begin{array}{l}\text { Short-term memory storage and } \\
\text { executive control }\end{array}$ & $\mathrm{r}=0.047, \mathrm{p}=0.747$ & $\mathrm{r}=-0.005, \mathrm{p}=0.972$ \\
\hline
\end{tabular}

${ }^{*}$ Correlation is sig. at $\mathrm{p}<0.05 .{ }^{* *}$ Correlation is sig. at $\mathrm{p}<0.01$ 
the verbal fluency task (a measure of executive function), and flavonoid intake is supported by literature which suggests that executive function can be positively influenced by flavonoid supplementation and habitual flavonoid intake (40). The relationship between verbal fluency and intake of the flavonoid subclasses flavonols, flavan-3-ols and anthocyanins (but not flavanones, or flavones) may be related to the consumption of black and green tea (the major sources of flavonols and flavan3-ols) and berries (a major source of anthocyanins), in this group. The consumption of both green and black tea has been associated with improved cognition in older adults (41), although a recent systematic review considered the role of tea in mild-cognitive impairment and dementia progression and reported that the findings were too limited to draw conclusions (42). Similarly, the consumption of anthocyanin rich strawberries and blueberries has been associated slower cognitive decline (43).

The lack of correlation between total flavonoid intake and education, nutritional status and age indicates that in this cohort these factors do not impact on total flavonoid consumption. This may be explained by tea consumption, the largest contributor to total flavonoid intake being a universally consumed item by all socioeconomic groups, and also reflects the lack of energy or micronutrients provided by this beverage, thus not impacting on nutritional status.

The positive association between depressive symptomatology (as measured by GDS) and flavonoid intake ( $\mathrm{r}=-0.367, \mathrm{p}=0.009)$ is interesting. The reduction in association between verbal fluency and flavonoid intake when depression was included as a covariate suggests that this relationship is confounded by the effect of depression on executive functioning. We speculate that epidemiological studies that have reported associations between flavonoid intake and cognitive outcomes, without controlling for depression, may have overestimated the strength of this relationship (7).

There is little consensus regarding which cognitive domain is impacted by flavonoid intake $(40,44)$ or which tool should be employed to measure this effect (44). We therefore used a battery of cognitive tests in order to investigate a wide range of domains of cognitive function, ensuring that each of the validated tests was sensitive and specific. Generalizability of the study findings is limited by the small sample size and the non representative nature of the convenience study sample. Other limitations include the inadequacy of using a single $24 \mathrm{~h}$ dietary recall to estimate habitual dietary flavonoid intake. Aside from the limitations associated with this dietary assessment method, there are several well documented problems associated with utilising food composition databases to assign flavonoid content to selected foods to reflect dietary intake. These limitations include an incomplete list of flavonoid containing foods, non-regional specific data (there is no Australian database for the flavonoid content of foods comprising the Australian food supply), and the inability of a dietary assessment to account for the high intra-individual variation of flavonoid absorption and metabolism (45). These limitations may result large variations in estimations of flavonoid intake (6) that differ from the true value, and may hinder our interpretation of observational data that associates flavonoid intake with specific health outcomes.

In conclusion, dietary intake of flavonoids in a sample of older adults with Alzheimer's disease was found to be somewhat lower than current Australian estimations for this age group, but the contributions of dietary sources are similar to the general older population. The identified association between cognitive functioning, depression and flavonoid intake in older adults with Alzheimer's type dementia warrants further research in a larger sample to confirm the findings and to identify whether dietary interventions may be indicated.

Funding: This study was conducted with funding from the Illawarra Health and Medical Research Institute. The sponsors had no role in the design and conduct of the study; in the collection, analysis, and interpretation of data; in the preparation of the manuscript; or in the review or approval of the manuscript.

\section{Acknowledgements: None}

Conflict of interest: None

Ethical standards: This study was approved by the University of Wollongong and Illawarra Shoalhaven Local Health District Human Research Ethics Committee (HE11/175) and complied with current laws governing ethics in research.

\section{References}

1. Spencer JPE. Flavonoids: modulators of brain function? British Journal of Nutrition. 2008;99(E-S1):ES60-ES77.

2. Vauzour D, Vafeiadou K, Rodriguez-Mateos A, Rendeiro C, Spencer JPE. The neuroprotective potential of flavonoids: a multiplicity of effects. Genes Nutr. 2008;3(3):115-26.

3. Engelhart MJ, Ruitenberg A, Geerlings MI, Hofman A, van Swieten JC, Breteler MMB, et al. Dietary Intake of Antioxidants and Risk of Alzheimer Disease. The Journal of the American Medical Association. 2002;287(24):3223-9.

4. Somerset SM, Johannot L. Dietary flavonoid sources in Australian adults. Nutrition and cancer. 2008;60(4):442.

5. Kent K, Charlton KE Russell J, Mitchell P, Flood VM. Estimation of Flavonoid Intake in Older Australians: Secondary Data Analysis of the Blue Mountains Eye Study. Journal of Nutrition in Gerontology and Geriatrics. 2015;34(4):38898.

6. Chun OK, Lee SG, Wang Y, Vance T, Song WO. Estimated flavonoid intake of the elderly in the United States and around the world. J Nutr Gerontol Geriatr. 2012 Jul;31(3):190-205.

7. Letenneur L, Proust-Lima C, Le Gouge A, Dartigues JF, Barberger-Gateau P. Flavonoid intake and cognitive decline over a 10-year period. Am J Epidemiol. 2007 Jun 15;165(12):1364-71.

8. Butchart C, Kyle J, McNeill G, Corley J, Gow AJ, Starr JM, et al. Flavonoid intake in relation to cognitive function in later life in the Lothian Birth Cohort 1936. Br J Nutr. 2011 Jul;106(1):141-8.

9. Nurk E, Refsum H, Drevon CA, Tell GS, Nygaard HA, Engedal K, et al. Intake of flavonoid-rich wine, tea, and chocolate by elderly men and women is associated with better cognitive test performance. J Nutr. 2009 Jan;139(1):120-7.

10. Spencer JPE. The impact of fruit flavonoids on memory and cognition. British Journal of Nutrition. 2010;104(S3):S40-S7.

11. Andres-Lacueva C, Shukitt-Hale B, Galli RL, Jauregui O, Lamuela-Raventos RM, Joseph JA. Anthocyanins in aged blueberry-fed rats are found centrally and may enhance memory. Nutritional Neuroscience. 2005;8(2):111-20.

12. Galli RL, Shukitt-Hale B, Youdim KA, Joseph JA. Fruit polyphenolics and brain aging: Nutritional interventions targeting age-related neuronal and behavioral deficits. Ann N Y Acad Sci. 2002;959(1):128-32.

13. Joseph JA, Shukitt-Hale B, Denisova NA, Bielinski D, Martin A, McEwen JJ, et 
al. Reversals of age-related declines in neuronal signal transduction, cognitive, and motor behavioral deficits with blueberry, spinach, or strawberry dietary supplementation. Journal of Neuroscience. 1999;19(18):8114-21.

14. Krikorian R, Boespflug EL, Fleck DE, Stein AL, Wightman JD, Shidler MD, et al. Concord Grape Juice Supplementation and Neurocognitive Function in Human Aging. J Agric Food Chem. 2012;60(23):5736-42.

15. Krikorian R, Nash TA, Shidler MD, Shukitt-Hale B, Joseph JA. Concord grape juice supplementation improves memory function in older adults with mild cognitive impairment. British Journal of Nutrition. 2010;103(5):730-4.

16. Krikorian R, Shidler MD, Nash TA, Kalt W, Vinqvist-Tymchuk MR, ShukittHale B, et al. Blueberry supplementation improves memory in older adults. J Agric Food Chem. 2010;58(7):3996-4000.

17. Kent K, Charlton K, Roodenrys S, Batterham M, Potter I, Traynor V, et al. Consumption of anthocyanin-rich cherry juice for 12 weeks improves memory and cognition in older adults with mild-to-moderate dementia. Eur J Nutr. 2015.

18. Whyte AR, Williams CM. Effects of a single dose of a flavonoid-rich blueberry drink on memory in 8 to 10 y old children. Nutrition.31(3):531-4.

19. Commenges D, Scotet V, Renaud S, Jacqmin-Gadda H, Barberger-Gateau P, Dartigues JF. Intake of flavonoids and risk of dementia. European Journal of Epidemiology. 2000;16(4):357-63.

20. Li R, Huang Yg Fau - Fang D, Fang D Fau - Le W-D, Le WD. (-)-Epigallocatechin gallate inhibits lipopolysaccharide-induced microglial activation and protects against inflammation-mediated dopaminergic neuronal injury. J Neurosci Res. 2004;78(5):723-31.

21. Vauzour D, Vafeiadou K, Rice-Evans C, Williams RJ, Spencer JPE. Activation of pro-survival Akt and ERK1/2 signalling pathways underlie the anti-apoptotic effects of flavanones in cortical neurons. J Neurochem. 2007;103(4):1355-67.

22. Fisher. Cocoa Flavanols and Brain Perfusion. J Cardiovasc Pharmacol. 2006;47:S210-S4.

23. Orhan IE, Daglia M, Nabavi SF, Nabavi SM, Loizzo MR, Sobarzo-Sánchez E. Flavonoids and dementia: An update. Curr Med Chem. 2015;22(8):1004-15.

24. Dai Q, Borenstein AR, Wu Y, Jackson JC, Larson EB. Fruit and Vegetable Juices and Alzheimer's Disease: The Kame Project. The American journal of medicine. 2006;119(9):751-9.

25. Barnerger-Gateau P, Raffaitin C, Letenneur L, Berr C, Tzourio C, Dartigues JF, et al. Dietary patterns and risk of dementia: the Three-City cohort study. Neurology 2007;69(20):1921-30 10p.

26. Lin L-C, Watson R, Wu S-C. What is associated with low food intake in older people with dementia? Journal of Clinical Nursing. 2010;19(1-2):53-9.

27. Asai JL. Nutrition and the geriatric rehabilitation patient: challenges and solutions. Topics in Geriatric Rehabilitation. 2004;20(1):34-45 12p.

28. Software X. Foodworks. In: Xyris, editor. High Gate Hill, Qld, Australia.2009.

29. Bhagwat S, Haytowitz, DB, Holden, JM. USDA Database for the Flavonoid Content of Selected Foods Maryland: Nutrient Data Laboratory, U.S. Department of Agriculture 2013.

30. Cereda E. Mini Nutritional Assessment. Current opinion in clinical nutrition and metabolic care. 2012;15(1):29-41.
31. Liu KPY, Chan CCH, Chu MML, Ng TYL, Chu LW, Hui FSL, et al. Activities of daily living performance in dementia. Acta Neurologica Scandinavica. 2007;116(2):91-5.

32. Paradela EMP, Lourenço RA, Veras RP. Validation of geriatric depression scale in a general outpatient clinic. Revista de saúde pública. 2005;39(6):918-23.

33. Schoenberg MR, Dawson KA, Duff K, Patton D, Scott JG, Adams RL. Test performance and classification statistics for the Rey Auditory Verbal Learning Test in selected clinical samples. Archives of Clinical Neuropsychology. 2006;21(7):693-703.

34. Ross TP, Hanouskova E, Giarla K, Calhoun E, Tucker M. The reliability and validity of the self-ordered pointing task. Archives of Clinical Neuropsychology. 2007;22(4):449-58.

35. Calero MD, Arnedo ML, Elena N, Monica R-P, Cristobal C. Usefulness of 15-item version of the Boston Naming Test in neuopsychological assessment of low-educational elders with dementia. The Journals of Gerontology. 2002;57B(2):P187.

36. Pasquier F, Lebert F, Grymonprez L, Petit H. Verbal fluency in dementia of frontal lobe type and dementia of Alzheimer type. Journal of neurology, neurosurgery, and psychiatry. 1995;58(1):81-4.

37. Rasmusson DX, Zonderman AB, Kawas C, Resnick SM. Effects of age and dementia on the trail making test. Clinical neuropsychologist. 1998;12(2):16978 .

38. Gliko BT, Espe-Pfeifer P, Selden J, Escalona A, Golden CJ. Validity of Digit Span as a test for memory in dementia. Archives of Clinical Neuropsychology. 2000;15(8):737-.

39. Johannot L, Somerset SM. Age-related variations in flavonoid intake and sources in the Australian population. Public Health Nutr. 2006 Dec;9(8):104554.

40. Lamport DJD, Louise.; Wightman , JoLynne D.; Lawton, Clare L.; The effects of flavonoid and other polyphenol consumption on cognitive performance: A systematic research review of human experimental and epidemiological studies Nutrition and Aging. 2012;1(1):5-25.

41. Shen W, Xiao Y, Ying X, Li S, Zhai Y, Shang X, et al. Tea Consumption and Cognitive Impairment: A Cross-Sectional Study among Chinese Elderly. PLoS One. 2015;10(9):1-11.

42. Panza F, Barulli MR, Logroscino G, Seripa D, Pilotto A, Solfrizzi V, et al. Coffee, tea, and caffeine consumption and prevention of late-life cognitive decline and dementia: A systematic review. Journal of Nutrition, Health and Aging. 2014:16p.

43. Devore EE, Kang JH, Breteler MMB, Grodstein F. Dietary intakes of berries and flavonoids in relation to cognitive decline. Annals of Neurology. 2012;72(1):135-43.

44. Macready AL, Kennedy OB, Ellis JA, Williams CM, Spencer JPE, Butler LT. Flavonoids and cognitive function: a review of human randomized controlled trial studies and recommendations for future studies. Genes Nutr. 2009;4(4):227-42

45. Kay CD. The future of flavonoid research. Br J Nutr. 2010 Oct;104 Suppl 3:S91- 